\title{
AN APPRECIATION OF PRICE'S PRECIPITATION REACTION IN THE SEROLOGICAL DIAGNOSIS OF SYPHILIS*
}

BY

\author{
J. K. MASON AND C. HEADLAND \\ From the Royal Air Force Institute of Pathology and Tropical Medicine, \\ Halton, Buckinghamshire
}

\section{INTRODUCTION}

The precipitation reaction for the diagnosis of syphilis (PPR), introduced by Price in 1948, has been widely used in Great Britain, but few reports have so far been published evaluating the test as a diagnostic procedure (Singh and Sharma, 1951; Wilkinson, 1954 ; Evans, 1954).

Since April, 1953, this laboratory has been using it in parallel with the Wassermann (WR) and Kahn reactions as a battery of tests for the routine examination of sera, and 16,000 tests, including 716 positive in some degree, have now been performed. This paper analyses the results obtained and the value of the PPR with regard to sensitivity and specificity, both alone and in combination with the other reactions.

\section{MATERIALS AND METHODS}

Antigens.-Antigens for the Wassermann, Kahn, and PPR have been supplied throughout by the Venereal Disease Reference Laboratory (VDRL) through the courtesy of Dr. I. N. O. Price. The VDRL titre has been accepted in every case.

Complement.-Preserved complement obtained from the VDRL has been used generally but occasionally freeze-dried complement ("Lyovac") has been substituted. Complement titrations have followed the method of Price (1949b).

Haemolysin.-This has been obtained commercially. The titre is established for each bottle, and it has been shown to remain constant under good storage conditions.

Sheep Red Cells.-Defibrinated, formalized sheep blood has been obtained commercially. Cells over a week old have not been used.

Kahn Test.-The method employed has been that of Kahn (1928) save that the $3: 1$ serum/antigen tube has been omitted and an autoflocculation tube substituted. In addition, the serum has been pre-pipetted (Khairat, 1952).

\footnotetext{
* Received for publication June \&, 1955.
}

Price's Precipitation Reaction.-Price's technique (1948) has been followed in its entirety except for reporting. We have not used the method of units, quantitative results being expressed as the serum dilution only.

Wassermann Reaction.-The modifications introduced by Price (1950) have been followed.

Sera for Test.-Most of the specimens tested were sent to us by post, the serum having been separated before dispatch to us. Specimens obtained locally are normally submitted as whole blood, and the serum is separated immediately upon receipt. Since January, 1954, sera sent by post have been merthiolated (Croft and Smith, 1946). Our method has been to evaporate $0.5 \mathrm{ml}$. of $1: 1000$ tincture of merthiolate (Lilly) in bijou bottles at $60^{\circ} \mathrm{C}$. Because there is some evidence that merthiolate loses its potency with time, the prepared bottles have been distributed at weekly intervals to hospital laboratories. As nearly as possible $2.5 \mathrm{ml}$. of serum has been added to the bottle giving a final concentration of $1: 5000$ merthiolate in undiluted serum. Pending testing, sera have been stored at $-20^{\circ} \mathrm{C}$., inactivation being undertaken immediately before performing the flocculation tests. The two flocculation tests have been performed simultaneously twice weekly, the Wassermann reaction being done on the following day. Thus at the most 4 days have elapsed between receipt of sera and completion of the tests.

Reading of the Tests.-No quantitative Kahn test has been performed, the Kahn being reported as positive or negative. All positive PPRs and WRs have been titrated.

\section{ORIGINS OF THE SERIES}

The results reported are from 16,000 consecutive sera submitted to this laboratory between April, 1953, and April, 1955, on which a report on all three tests could be given. Specimens in which one or both of the flocculation tests showed autoflocculation or in which the WR was anticomplementary have been excluded. Most of the sera are from Royal Air Force personnel and their families stationed or admitted to hospital in the United 254 
TABLE I

ORIGINS OF THE SERIES ARRANGED ACCORDING TO ORIGINAL DIAGNOSIS

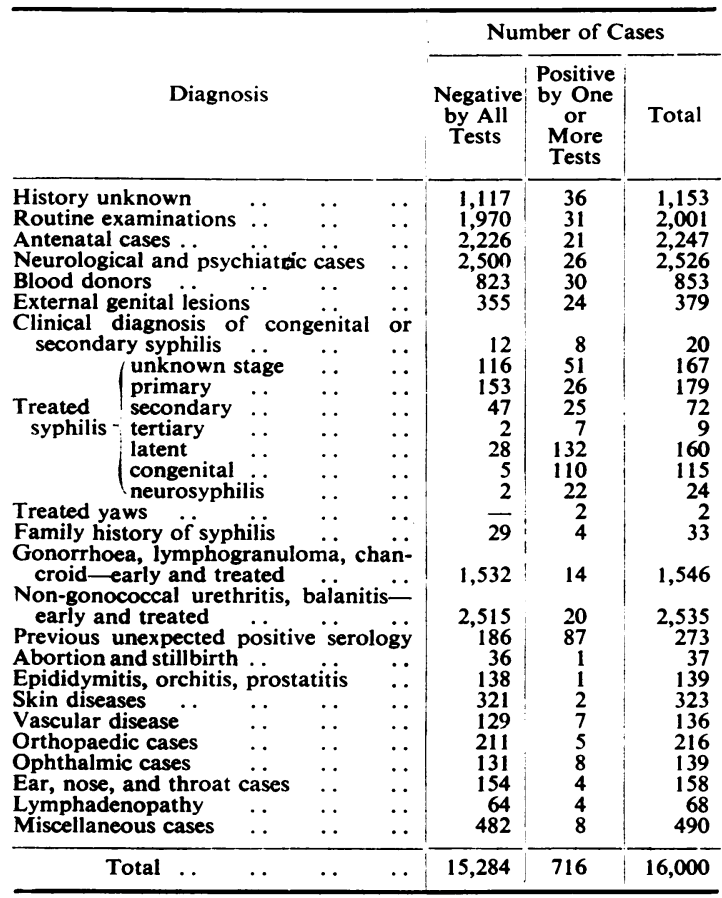

The routine examinations include such cases as fitness medicals, phobias, etc. Genital lesions include a number of conditions ranging from minor traumatic lesions to warts. The miscellaneous cases are predominantly from the general medical wards.

Kingdom or Western Europe. The origins of the specimens according to the diagnoses accompanying the sera are shown in Table I, in which certain points need emphasis. First, the diagnoses are provisional and in some cases were changed later ; the diagnoses in Table I and subsequent Tables do not, therefore, show absolute correlation. Secondly, the Table is an analysis of sera and not of cases. A large number of the specimens arise as a result of many tests being undertaken on the same patient, and Table I, therefore, gives no indication of the incidence of venereal disease in the Royal Air Force. Thirdly, the tendency to repeat tests of doubtful interpretation more frequently than those in which the serological and clinical diagnoses are mutually confirmatory exaggerates the incidence of biological false positive tests. Finally, the apparent, but fallacious, high incidence of positive tests obtained from blood donors arises because a large number of these specimens were selected as positive at laboratories of the National Blood Transfusion Service, particularly those concerned with the recruit centres mentioned later.

\section{RESULTS}

Of the 16,000 sera tested, 15,284 ( 95.53 per cent.). were non-reactive, while 716 (4.47 per cent.) were reactive with one or more of the tests used. The results are given in detail in Table II, which shows that all three reactions agreed in supporting the diagnosis of syphilis in 2.49 per cent. of specimens. There was thus full agreement between the three reactions in 98.02 per cent. of tests, which is rather greater than that obtained by Price (1948) and compares favourably with the results of Osmond (1950) contrasting the Wassermann and Kahn reactions.

There was disagreement in 317 tests $(1.98$ per cent. of the whole); the PPR agreed with the Kahn in 77 tests and with the WR in 120 tests. In the remaining 120 tests, the Wassermann and Kahn reactions agreed to the exclusion of the PPR.

The reactions in seventeen cases of early syphilis are analysed in Table III. All these cases were untreated primary syphilis except one (Case C525

TABLE III

REACTIONS OBTAINED FROM SEVENTEEN CASES OF ACUTE SYPHILIS

\begin{tabular}{|c|c|c|c|c|c|c|c|}
\hline Reaction & $\begin{cases}\text { Kahn } & \ldots \\
\text { PPR } & \ldots \\
\text { Wassermann }\end{cases}$ & $\begin{array}{l}\cdots \\
\cdots \\
\cdots\end{array}$ & $\begin{array}{l}+ \\
+ \\
+\end{array}$ & $\frac{1}{+}$ & $\bar{t}$ & $\bar{z}$ & Total \\
\hline Test $\left\{\begin{array}{l}\mathbf{F i} \\
\mathbf{S e}\end{array}\right.$ & $\begin{array}{l}\text { st diagnostic } \\
\text { cond confirmatory }\end{array}$ & $\therefore$ & $\begin{array}{l}10 \\
11\end{array}$ & $\begin{array}{l}4 \\
1\end{array}$ & $\underline{2}$ & 1 & $\begin{array}{l}17 \\
12\end{array}$ \\
\hline
\end{tabular}

TABLE II

ANALYSIS OF 716 POSITIVELY REACTING SERA FROM 16,000 TESTS

\begin{tabular}{|c|c|c|c|c|c|c|c|c|c|c|c|c|c|c|}
\hline Reaction ... & $\begin{array}{l}\text { Ka } \\
\text { PPI } \\
\mathbf{W a}\end{array}$ & $\begin{array}{l}\text { hn } \\
\text { ssermann }\end{array}$ & $\begin{array}{l}\ddot{*} \\
\cdots\end{array}$ & $\begin{array}{l}\cdots \\
\cdots\end{array}$ & $\begin{array}{l}\cdots \\
\cdots\end{array}$ & $\begin{array}{l}+ \\
+ \\
+\end{array}$ & $\begin{array}{l} \pm \\
-\end{array}$ & $\begin{array}{l}+ \\
+ \\
-\end{array}$ & $\begin{array}{l}+ \\
+\end{array}$ & $\begin{array}{l}- \\
+ \\
+\end{array}$ & $\begin{array}{l}- \\
+\end{array}$ & $\begin{array}{l}- \\
- \\
-\end{array}$ & Total & $\begin{array}{l}\text { Tests in } \\
\text { Series } \\
\text { (per cent.) }\end{array}$ \\
\hline $\begin{array}{c}\text { Diagnostic } \\
\text { Sera }\end{array}$ & $\begin{array}{l}\text { Tru } \\
\text { Fal } \\
\text { Un }\end{array}$ & $\begin{array}{l}\text { e syphilis } \\
\text { se positive } \\
\text { traceable }\end{array}$ & $\begin{array}{l}\cdots \\
\cdots \\
\cdots\end{array}$ & $\begin{array}{l}\cdots \\
\cdots \\
\cdots\end{array}$ & $\begin{array}{l}\cdots \\
\cdots \\
\cdots\end{array}$ & $\begin{array}{c}123(59) \\
5(5) \\
-\end{array}$ & $\begin{array}{r}1(1) \\
84(80) \\
1(1)\end{array}$ & $\begin{array}{l}3 \overline{(3)} \\
2(2)\end{array}$ & $\begin{array}{c}9(5) \\
30(20) \\
-\end{array}$ & $\begin{array}{l}\overline{1}(1) \\
1(1)\end{array}$ & $4 \overline{(3)}$ & $\begin{array}{c}2(2) \\
32(22) \\
3(3)\end{array}$ & $\begin{array}{r}135 \\
159 \\
7\end{array}$ & $\begin{array}{l}0.84 \\
0.99 \\
0.04\end{array}$ \\
\hline Treated Syphil & ilis & $\cdots$ & $\ldots$ & . & $\ldots$ & $271(81)$ & $26(21)$ & $4(3)$ & 76 (39) & $6(6)$ & $1(1)$ & $31(23)$ & 415 & $2 \cdot 59$ \\
\hline Total ... & . & . & $\ldots$ & $\cdots$ & $\cdots$ & 399 & 112 & 9 & 115 & 8 & 5 & 68 & 716 & $4 \cdot 47$ \\
\hline $\begin{array}{l}\text { Overall Inciden } \\
\text { Incidence in } \mathrm{Pc}\end{array}$ & ence ( & $\begin{array}{l}\text { Ter cent.) } \\
\text { Tests (per }\end{array}$ & ent.) & $\begin{array}{l}\cdots \\
\cdots\end{array}$ & 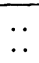 & $\begin{array}{c}2.49 \\
55 \cdot 7\end{array}$ & $\begin{array}{r}0.7 \\
15.6\end{array}$ & $\begin{array}{l}0.06 \\
1.2\end{array}$ & $\begin{array}{c}0.72 \\
16 \cdot 2\end{array}$ & $\begin{array}{l}0.05 \\
1.1\end{array}$ & $\begin{array}{l}0.03 \\
0.7\end{array}$ & $\begin{array}{l}0.42 \\
9.5\end{array}$ & & \\
\hline
\end{tabular}

The figures in parentheses indicate the number of patients from whom the sera were obtained. 
in Appendix). One case was negative to all three reactions at first test ; of the remainder, the Kahn was positive fourteen times, the PPR ten times, and the Wassermann sixteen times. Of the cases tested a second time before treatment was begun, only one failed to respond to all three reactions, and it seems that the diagnosis was open to doubt.

In Fig. 1 the titres obtained by the PPR and Wassermann techniques on identical specimens of serum are compared. All cases where a comparison was possible are included, but pre-treatment cases have been demarcated from the rest. Similar figures for the Kahn reaction cannot be produced because it was not performed quantitatively.

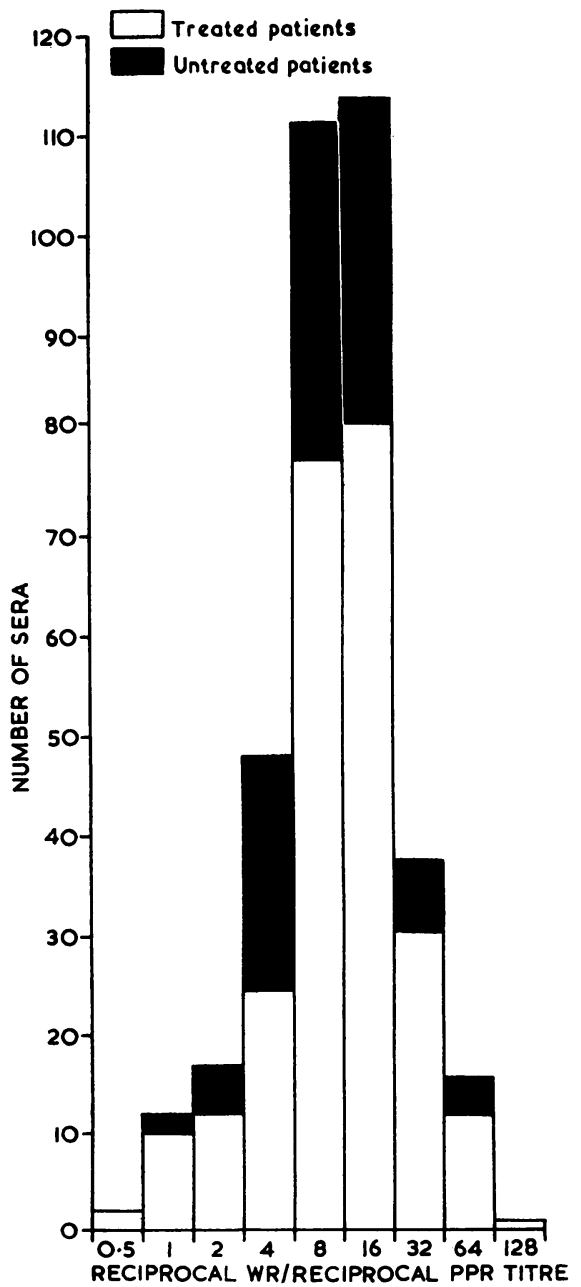

FIG. 1.-Comparative sensitivity of PPR and WR. Identical specimens of serum from treated and untreated syphilitics have been titrated by both techniques, the titres obtained having been expressed as a ratio.
The effect of treatment in each of the reactions in the test battery is shown in Table IV and diagrammatically in Fig. 2. Sera are included in which one or more reactions were positive, and the results are related to the time following treatment. The total number of tests in which there was sufficient information for inclusion in the Table was 330 , and in many cases the period of observation has been rather short. Where the total number of tests performed at a given time was less than ten, the points have not been plotted in Fig. 2.

The number of times each reaction, if used alone or in conjunction with another one, would have failed to demonstrate a treated syphilitic who was still reactive, is shown in Table $\mathrm{V}$ (opposite). From this it will be seen that the PPR if used alone would have failed to pick up such a case in 32 per cent. of the tests as opposed to $9 \cdot 1$ per cent. for the Kahn and 7.5 per cent. for the WR. A combination of the

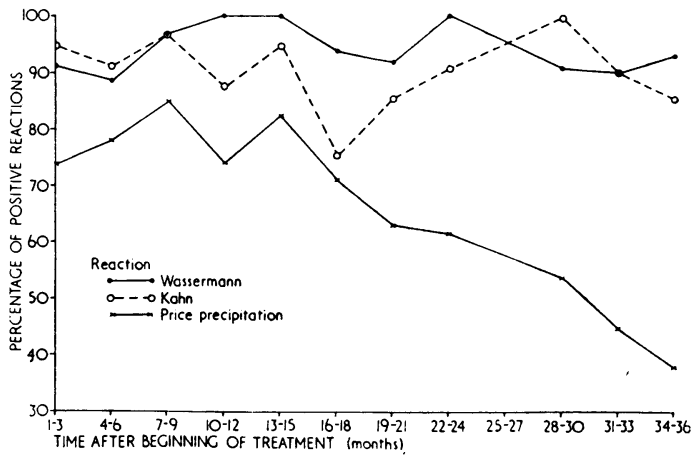

FIG. 2.-Response to treatment of the PPR, WR, and Kahn. Treated cases still showing reactivity to one or more tests have been collected in groups according to the time following treatment. The number of positive reactions given by each test is expressed as a percentage of the group. Wholly negative sera are not included.

TABLE IV

POSITIVE REACTIONS OBTAINED WITH THE THREE REACTIONS RELATED TO TIME AFTER TREATMENT OF PROVEN SYPHILIS

\begin{tabular}{c:c:ccc}
\hline $\begin{array}{c}\text { Time } \\
\text { after } \\
\text { Treatment } \\
\text { (mths) }\end{array}$ & $\begin{array}{c}\text { Total } \\
\text { Positive by } \\
\text { One or More } \\
\text { Reactions }\end{array}$ & $\begin{array}{c}\text { Kahn } \\
+\end{array}$ & $\begin{array}{c}\text { Reaction } \\
\text { PPR }\end{array}$ & $\begin{array}{c}\text { Wassermann } \\
+\end{array}$ \\
\hline $1-3$ & 52 & 50 & 39 & 48 \\
$4-6$ & 65 & 59 & 51 & 58 \\
$7-9$ & 39 & 38 & 33 & 38 \\
$10-12$ & 32 & 28 & 24 & 32 \\
$13-15$ & 23 & 22 & 19 & 23 \\
$16-18$ & 21 & 16 & 15 & 20 \\
$19-21$ & 16 & 14 & 10 & 15 \\
$22-24$ & 13 & 12 & 8 & 13 \\
$25-27$ & 9 & 8 & 7 & 9 \\
$28-30$ & 13 & 13 & 7 & 12 \\
$31-33$ & 11 & 10 & 5 & 10 \\
$34-36$ & 16 & 14 & 6 & 15 \\
$37-39$ & 9 & 8 & 5 & 8 \\
$40-42$ & 5 & 4 & 2 & 4 \\
$43-45$ & 2 & 1 & 0 & 2 \\
$46-48$ & 1 & 0 & 1 & 1 \\
$49-51$ & 3 & 3 & 2 & 3 \\
\hline
\end{tabular}


TABLE V

REAGIN CONTAINING SERA FROM TREATED SYPHILIS ; RELATIVE SENSITIVITIES OF THE THREE REACTIONS

\begin{tabular}{|c|c|c|c|c|c|c|}
\hline \multirow{2}{*}{\multicolumn{4}{|c|}{ Reaction }} & \multicolumn{2}{|c|}{ Results } & \multirow{2}{*}{$\begin{array}{c}\begin{array}{c}\text { Per cent. } \\
\text { Non- } \\
\text { reactors }\end{array} \\
-\end{array}$} \\
\hline & & & & $\frac{\text { Positive }}{415}$ & $\frac{\text { Negative }}{-}$ & \\
\hline $\begin{array}{l}\text { Total } \\
\text { Kahn } \\
\text { PPR } \\
\text { Wasserma } \\
\text { Kahn + P } \\
\text { Wasserma } \\
\text { Kahn + W }\end{array}$ & $\begin{array}{l}\ldots \\
\cdots \\
\cdots \\
\text { ann } \\
\text { Pann } \\
\text { Nasserr }\end{array}$ & $\begin{array}{l}\ddot{ } \\
\ddot{*} \\
\ddot{P} \\
\ddot{\text { PRR }}\end{array}$ & \begin{tabular}{l|}
$\cdots$ \\
$\cdots$ \\
$\cdots$ \\
$\cdots$ \\
$\cdots$ \\
$\cdots$
\end{tabular} & $\begin{array}{l}415 \\
377 \\
282 \\
384 \\
384 \\
389 \\
414\end{array}$ & $\begin{array}{r}738 \\
133 \\
31 \\
31 \\
26 \\
1\end{array}$ & $\begin{array}{r}7.1 \\
32.0 \\
7.5 \\
7 \cdot 5 \\
6 \cdot 3 \\
0.2\end{array}$ \\
\hline
\end{tabular}

PPR and Kahn would have missed 7.5 per cent., the PPR and the WR 6.3 per cent., while the WR and Kahn combined would have failed in only 0.2 per cent.

In positive tests regarded as false, the PPR was positive thirteen times, the WR 68 , and the Kahn 122 times. A positive result has been assessed as false if it was never reproducible in the untreated patient (technical false positive) or if the serum reaction showed steady reversion to negative on serial testing in the absence of treatment (biologic false positive). Occasional sera which have not reverted to normal have been classified as biologic false positive on a purely clinical basis. The results in the $\mathbf{1 5 9}$ false positive diagnostic tests are further

TABLE VI

INCIDENCE OF FALSE POSITIVE TESTS IN THE SERIES AND RELATIVE SPECIFICITIES OF THE THREE REACTIONS

\begin{tabular}{|c|c|c|c|c|}
\hline Incidence of Fals & Positive Results & $\begin{array}{l}\text { Overall } \\
\text { (per } \\
\text { cent.) }\end{array}$ & $\begin{array}{c}\text { In } \\
\text { Positive } \\
\text { Tests } \\
\text { (per } \\
\text { cent.) }\end{array}$ & $\begin{array}{l}\text { In } \\
\text { Positive } \\
\text { Diag- } \\
\text { nostic } \\
\text { Tests } \\
\text { (per } \\
\text { cent.) }\end{array}$ \\
\hline $\begin{array}{l}\text { Sero-positivity } \\
\text { judged by }\end{array}$ & $\begin{array}{l}\text { One test only } \\
\text { positive } \\
\text { Flocculation } \\
\text { and comple- } \\
\text { ment-fixation } \\
\text { tests both } \\
\text { positive } . \\
\text { All three reac- } \\
\text { tions positive }\end{array}$ & $\begin{array}{l}0.23 \\
0.03\end{array}$ & $\begin{array}{l}5 \cdot 1 \\
0 \cdot 7\end{array}$ & $\begin{array}{r}12 \cdot 3 \\
1 \cdot 7\end{array}$ \\
\hline $\begin{array}{l}\text { Incidence of false } \\
\text { positive tests } \\
\text { given by individual } \\
\text { reactions }\end{array}$ & $\begin{array}{lll}\text { Kahn } & \ldots & \ldots \\
\text { PPR } & \ldots & \ldots \\
\text { Wassermann } & \ldots\end{array}$ & $\begin{array}{l}0.76 \\
0.08 \\
0.43\end{array}$ & $\begin{array}{r}17 \cdot 2 \\
1 \cdot 8 \\
9 \cdot 7\end{array}$ & $\begin{array}{r}41 \cdot 5 \\
4 \cdot 4 \\
23 \cdot 1\end{array}$ \\
\hline
\end{tabular}

elaborated in Table VI. The overall incidence of false positive serology was almost exactly 1 per cent., which is higher than would be anticipated (Wolman, 1946 ; Stokes and James, 1949; Price, 1954). More than half the false positive tests arose as a result of an isolated false positive Kahn reaction -a finding which is so common (Bossak and others, 1953 ; Fischer, 1950; Levitan and others, 1952) that a diagnosis of syphilis on such grounds would be unthinkable. If a positive flocculation test together with a positive complement-fixation test is taken as the minimum finding compatible with the serological diagnosis of syphilis (Beelar, Zimmerman and Manchester, 1949 ; Colquhoun, 1950), the overall incidence of false positive serology is reduced to 0.23 per cent., and the percentage of positive diagnostic tests ultimately considered false is reduced from $54 \cdot 1$ per cent. for a single test to 12.3 per cent. If full agreement of all three tests were to be taken as the criterion for the sero-diagnosis of syphilis, an incidence of a false positive diagnosis of syphilis in 1.7 per cent. of positive diagnostic tests would arise. This rigid principle would also involve the failure to diagnose syphilis in 8.8 per cent. of sera from untreated cases.

It is impossible from our records to estimate the number of times all three reactions were falsely negative together.

\section{DISCUSSION}

\section{Sensitivity of the Reactions}

There are various ways in which the sensitivity of the PPR can be compared with the sensitivity of the other tests.

First, an analysis of very early cases of syphilis can be made and the order in which the reactions normally became positive can be assessed. Table III, which shows the results in such patients, offers some evidence that, of the three reactions under consideration, the PPR is the least sensitive in early syphilis, failing to identify seven out of seventeen cases. Price's results in 1948 showed that the Kahn was superior to the PPR in this respect, but at this time the Wassermann was not attuned to such a degree of sensitivity. It is interesting to note that, using Price's modification of the Wassermann reaction (Price, 1950), only one case of early syphilis, which was negative to all three reactions, would have been missed at first test. Moreover, of the seventeen cases, eight showed a Wassermann titre of $1: 128$ or higher before treatment began.

Secondly, the relative sensitivity of the tests under consideration could be judged by comparing the titres obtained on identical specimens of serum from known cases of syphilis. Fig. 1 shows that, when pre-treatment cases only are considered, the PPR was never more sensitive than the WR and that in the majority of cases the WR was four to sixteen times more sensitive than the PPR, a finding which coincides with that of Price (1949a). When all sera showing a positive Wassermann and PPR, including those from treated cases, are considered, it will be seen that the pattern of results is not materially altered though the superior sensitivity of the Wassermann reaction is, perhaps, rather more accentuated. 
Thirdly, the sensitivity may be compared by following the effect of treatment on each reaction. The results in Table IV and the comparative slopes of the graph in Fig. 2 show clearly that there is a tendency for the PPR to revert to normal before the Wassermann and the Kahn. The final evidence as to the relative sensitivity of the three reactions is contained in Table $V$. The results give a definite impression that the PPR is markedly less sensitive than either the Kahn or the Wassermann reaction. In both these cases the assessment of sensitivity is based on the assumption that persistence of one positive serological reaction indicates incomplete surveillance-a highly suspect belief (Heywood, 1952 ; Redmond, Nicol, and Shooter, 1952; Cannefax and Johnwick, 1954). It is possible that a careful clinico-serological survey might find that the apparent insensitivity of the PPR was a definite advantage in assessing the results of treatment.

Until further information is available, however, it is clear that the PPR is insufficiently sensitive for use as a screening test and should never be used as a single reaction for the exclusion of syphilis.

\section{Specificity of the Reactions}

The specificity of a reaction can be judged only by the number of false positive results it gives. Before considering the individual reactions it seems necessary to investigate the causes of the rather high general incidence of false positive tests in our series.

One possibility is that the general laboratory technique is at fault. Such an explanation could be tenable so far as the isolated positive Kahn test is concerned. If these tests are divided into those before 1954 and those in 1954 and onwards it is found that the incidence of the isolated false positive Kahn before 1954 was 0.64 per cent. while from 1954 onwards it was 0.43 per cent. Of the 1954 cases, 71 per cent. were in the first half of the year, while this false positive reaction has not been seen in the early part of 1955 covered by this series. We believe this decline to be associated with the gradual introduction of prepared merthiolate bottles in January, 1954. The Kahn reaction appears to be hypersensitive to the effects of travel (Sautet, 1951), such effects being largely beyond the control of the laboratory although merthiolate seems to improve the position (Rein and Kelcec, 1954).

Even so, the incidence of positive Kahn tests is higher than we should like, and for further relevant information we are indebted to Knox (1955), who collected information from 4,800 volunteer blood donors from healthy recruits to the Royal Air Force and found that 104 (2.2 per cent.) were rejected by the Transfusion Service as a result of a positive Kahn being obtained. During the period January to June, 1954, another recruit centre, largely Women's Royal Air Force, had 34 similar rejections, and a third, the largest of the three, 73. In the last two cases the percentage of rejection is not available. It would, therefore, seem that false positive serology is a general finding in groups comparable to ours and not an isolated occurrence in one laboratory.

The combination of false positive Kahn and Wassermann reactions has occurred in 0.22 per cent. of tests in our series, a frequency which constitutes a serious problem because a patient giving such a result stands in grave danger of being diagnosed as syphilitic. This reaction was also obtained in eleven blood donors from the Women's Royal Air Force centre and in nineteen donors from the largest recruit centre, but, again, the incidence is not available. It is interesting to note that Price (1948) did not obtain such a result in his series.

We are convinced that, while many of the results which show a positive Kahn only can be ascribed to postal or storage effects, the combination of false positive Kahn and Wassermann reactions is a definite biological entity which is curiously prevalent in our series and in the comparable groups reported by Knox (1955). We believe that this is due to the high state of active immunization effected in the Armed Forces. Many authors (Davis, 1944 ; Rein and Elsberg, 1945 ; Perrot, 1948 ; Stokes and James, 1949 ; Mahoney and Zwally, 1949 ; Kay and Rice, 1951 ; Archambault, 1951 ; Price, 1954) agree that this may be a potent cause of false positive reactions for syphilis, though Rosenthal and Widelock (1948) think the risk to be exaggerated. In our present series the results are not particularly helpful because of lack of relevant histories. Some suggestive evidence can, however, be gained from the 4,800 blood donors mentioned above. All these persons had been vaccinated against smallpox shortly before the test, the average being 4 weeks. On the other hand, almost exactly 50 per cent. of the 104 positives had deliberately been excluded from the routine TABT immunization offered to R.A.F. recruits; TABT inoculation might, therefore, be excluded as a cause of false positive syphilitic serology. Subsequently, Knox arranged for a group of blood donor volunteers to be tested before vaccination : 980 tests were made and the incidence of false positive serology was reported as nil. There is thus some evidence that vaccination against smallpox may give up to 2 per cent. of false positive results, a situation which is of the utmost importance in groups such as the Armed Forces and particularly where a sensitive Wassermann 
technique is in use. Many of the false positive tests previously reported from this laboratory (Roberts and Swale, 1949) probably fall into this group.

The second most frequent pattern of false positive tests was that which showed a positive complementfixation test only. In view of the generally accepted superiority of the complement-fixation test as regards specificity (Fischer, 1950; Bossak and others, 1953 ; Pecora, 1953), this is an important group. In four cases (five tests) the positive Wassermann reaction was the final stage in a steady gradation from a combined false Kahn and false Wassermann, the Wassermann persisting longer (Case G231 in the Appendix is a typical example).

In eighteen cases ( 27 tests) the Wassermann was the only one of the three reactions in use ever to be positive-one particularly interesting case was B35 in the Appendix. Three of these tests on sera from three healthy babies born to syphilitic mothers who were under treatment were due to a carry-over of maternal reagin (Bundesen and Aron, 1950; Denecke, 1951). It is important to note that Price's modification of the Wassermann reaction may produce false positive results without similar flocculation results in up to 10 per cent. of the total positive sera submitted for diagnosis.

The small group of five patients in which all three reactions were falsely positive is most important. Two of these false positives almost certainly arose as a result of clerical error and substitution of specimens. One was a very weak reaction throughout and the other two were definite positives and were only proved to be biologic false positives by careful follow-up. Both the latter had recently been vaccinated against smallpox.

The remaining eight false positive tests consist of four tests (three patients) in which the PPR was positive in low titre when both Wassermann and Kahn were negative, three in which the flocculation tests were weakly positive in the presence of a negative complement-fixation test, and one where the Kahn was the only negative reaction of the three. Apart from the five cases in which all the reactions were positive, these eight tests represent the only failures of the PPR in the series in regard to specificity.

The specificity of the PPR (Table VI) is quite remarkable, and we have increasingly come to regard the PPR as the most useful reaction in the evaluation of a positive diagnostic test. A positive PPR appears to be the best " standard" serological evidence of active syphilitic infection available. If the Wassermann reaction is also positive, the case for diagnosing syphilis is extremely good, providing steps are taken to exclude clerical error. In such circumstances, only 1.4 per cent. of positive diagnostic tests would eventually prove to be false and some of these should be anticipated by the generally low titre of the PPR (Case C19 in Appendix). Another great value of the PPR is demonstrated by the fact that, of 33 sera from non-syphilitic persons giving a positive Kahn and Wassermann test of sufficient clarity to warrant a tentative diagnosis of syphilis, the PPR indicated the incorrectness of the result in all but three. The value of the PPR is, however, limited when no clinical history is available, as a negative reaction can well occur in early untreated or late treated syphilis.

It may be argued that the specificity of the PPR is merely a reflection of its diminished sensitivity. This may be true in part, but we do not think it the whole explanation. In the first place the combination "Wassermann +, Kahn +, PPR - " occurs as a false positive so frequently that it is hard to avoid attributing the negative PPR to specificity. Secondly, several of our false positive cases have had WR titres in excess of $1: 128$ together with a negative PPR. Such a discrepancy is hardly explicable purely on the basis of relative sensitivity. Finally, it seems unlikely that the great excess of "Wassermann -, Kahn +, PPR - " reactions over "Wassermann -, Kahn +, PPR + " can be put down solely to a difference in sensitivity.

\section{PRACTICAL APPLICATION}

No serological test could be simpler to perform than the PPR. The antigen is easy to prepare and is stable under a wide range of temperature conditions (Macfarlane, Anderson, and Pinion, 1953 ; Evans, 1954). We have, however, found that a very fine flocculation is invariably present in the negative controls and, for this reason, we strongly advocate reading the PPR before other flocculation tests; the reverse will lead to prejudiced reading of the PPR.

The very high degree of specificity of the PPR found in this series suggests that it is a reaction which could with advantage be used as a routine. To use the reaction by itself as a screening test, say of blood donors, is strongly contraindicated, since a high percentage of incompletely followed cases of syphilis will be missed. For use in any sphere, the PPR must be combined with one or more reactions of superior sensitivity.

Probably the commonest combination of tests in use in Great Britain is that of the Wassermann and Kahn reactions. We find that both these reactions have very much the same sensitivity. The Wassermann reaction appears to be the rather more specific, 
but the routine use of merthiolate may remove this apparent advantage. There is a tendency for a biologic false positive Wassermann to persist longer than a similar Kahn reaction, and in treated cases of late syphilis the Wassermann takes rather longer to reach normal than the Kahn ; in early syphilis the reverse tends to occur. All in all, there seems little to choose between the reactions and it might be possible to substitute one or the other by the PPR and thus to improve the test battery without complicating it.

The combination of the Wassermann and PPR without the Kahn would result in the elimination of over 50 per cent. of the false positive results in the present series. On the other hand, one early case of syphilis would have been missed and $6 \cdot 3$ per cent. of reagin-containing sera from treated syphilitics would have been reported as seronegative, though whether this would be a disadvantage, in view of the highly non-specific nature of the isolated positive Kahn, is at least arguable. It would seem that the Kahn reaction could be eliminated without loss of efficiency. However, the Price modification of the Wassermann reaction is not easy to carry out, and it is desirable to have a highly sensitive flocculation test on hand as a check on possible technical false positive complement-fixation tests. To carry out the Kahn test in parallel with the PPR involves very little extra work and, on the whole, we would advocate its retention.

If the Wassermann reaction could be discarded, much time and effort would be saved. In this series, such a practice would have resulted in two cases of early syphilis being missed and $7 \cdot 5$ per cent. of treated syphilitic reagin-containing sera being classed as negative. Twenty per cent. of false positive reactions would have been eliminated. Thus, for a small laboratory with a shortage of skilled technicians, a test battery of Kahn and PPR would give results of reasonable efficiency. Whenever possible, however, we would advocate the inclusion of the Wassermann in the test reactions. It has historic merit and is the test invariably requested by clinicians; it involves a technique wholly different from that required for flocculation tests, which, combined with the fact that it is usually performed on a different day, tends to eliminate false positive results due to laboratory error ; finally, only the inclusion of a complementfixation test can be expected to eliminate the prozone exhibited by some strongly reactive sera (Beelar and others, 1949).

In tropical conditions, where the WR is notoriously fickle and the reagents hard to keep, the Kahn and PPR used alone might prove to be the best test battery available. In normal circumstances, however, we feel that the PPR, valuable test though it is, cannot completely replace the Kahn or Wassermann reactions. The performance of the Wassermann, Kahn, and Price reactions in parallel appears to be a highly effective and relatively simple method of diagnosing or eliminating syphilis.

\section{SUMMARY}

The results of submitting 16,000 consecutive sera to test by the Kahn, Wassermann, and Price Precipitation reactions are presented, and the usefulness of the PPR is compared with that of the other two tests.

The PPR is shown to be more specific than either of the other reactions, but is less sensitive as measured by the effect of treatment on the serum reactions.

The incidence of false positive tests for syphilis in the series is discussed and a possible reason for the high incidence elaborated.

The constitution of a simple test battery is discussed. It is considered that a combination of Kahn, PPR, and Wassermann is nearly ideal. In circumstances where the carrying out of the Wassermann is contraindicated, a combination of the Kahn test and the PPR will give reasonably accurate results.

We are indebted to our fellow officers and technicians who have given us all possible help throughout this investigation. We should particularly like to thank the officers in charge of several hospital laboratories who have gone to much trouble to trace patients' records for us. In this respect our especial thanks are due to Squadron Leaders A. N. Kingon and C. S. Pitcher, the officers in charge of the Special Treatment Centres in the United Kingdom and Western Europe respectively. Our thanks are also due to the Director General of Medical Services, Royal Air Force, who has kindly given us permission to publish this paper.

\section{REFERENCES}

Archambault, J. (1951). Canad. J. Publ. Hlth, 42, 323.

Beelar, V. P., Zimmerman, H. J., and Manchester, B. (1949). Amer. J. med. Sci., 217, 658.

Bossak, H. N., Harris, A., Duncan, W. P., Olansky, S., and Chester, B. J. (1953). Amer. J. Syph., 37, 536.

Bundesen, H. N., and Aron, H. C. S. (1950). J. vener. Dis. Inform., $31,185$.

Cannefax, G. R., and Johnwick, E. B. (1954). Amer. J. Syph., 38, 18. Colquhoun, D. B. (1950). British Journal of Venereal Diseases, 26, 139.

Croft, C. C., and Smith, L. L. (1946). J. Lab. clin. Med., 31, 1101. Davis, B. D. (1944). Medicine (Baltimore), 23, 359.

Denecke, K. (1951). Z. ImmunForsch., 108, 266.

Evans, A. J. (1954). British Journal of Venereal Diseases, 30, 212.

Fischer, E. (1950). Schweiz. med. Wschr., 80, 1311.

Heywood, C. P. (1952). British Journal of Venereal Diseases, 28, 3.

Kahn, R. L. (1928). "The Kahn Test. A Practical Guide." Williams and Wilkins, Baltimore.

Kay, W. W., and Rice, D. (1951). Lancet, 2, 40.

Khairat, O. (1952). Brit. med . J., 1, 582.

Knox, J. (1955). Personal communication. 
Levitan, S., Aragon, H. A., Cutler, J. C., Funes, J. M., Portnoy, J., and Paredes-Luna, A. (1952). Amer. J. Syph., 36, 379.

Macfarlane, L. R. S., Anderson, C. K., and Pinion, F. C. (1953). British Journal of Venereal Diseases, 29, 236.

Mahoney, J. F., and Zwally, M. R. (1949). Bull. Wld Hlth Org., 2, 227.

Osmond, T. E. (1950). Brit. med. J., 1, 524.

Paillard, R., and Bolay, G. (1951). Schweiz. med. Wschr., 81, 235.

Pecora, G. (1953). Nuovi Ann. Ig., 4, 440.

Perrot, H. (1948). Bull. Soc. méd. Hóp., Paris, 64, 124

Price, I. N. O. (1948). J. clin. Path., 1, 91.

- (1949a). British Journal of Venereal Diseases, 25, 67.

(1949b). Ibid., 25, 157.

- (1950). Ibid., 26, 172.
Price, I. N. O. (1954). Brit. med. J., 1, 637.

Redmond, A., Nicol, C. S., and Shooter, R. A. (1952). Britisht Journal of Venereal Diseases, 28, 13.

Rein, C. R., and Elsberg, E. S. (1945). Amer. J. Syph., 29, 303.

- and Kelcec, L. C. (1954). Ibid., 38, 308.

Roberts, G. F., and Swale, J. (1949). J. Hyg. (Lond.), 47, 263.

Rosenthal, T., and Widelock, D. (1948). Amer. J. Syph., 32, 365.

Sautet, J. (1951). Rev. Serv. Santé publ. Guadaloupe, 2, no. 5, p. 55.

Singh, B., and Sharma, M. D. (1951). British Journal of Venereal Diseases, 27, 190.

Stokes, J. H., and James, G. W. (1949). Amer. J. Syph., 33, 114.

Wilkinson, A. E. (1954). British Journal of Venereal Diseases, 30, 144. Wolman, I. J. (1946). Amer. J. med. Sci., 212, 280.

\section{A P P E N D I X}

\section{Case Reports}

Case B35.-A young airman traumatized his genitalia, and 10 days later was found to have a Wassermann reaction of titre 1:64 with negative Kahn and PPR. One month later the Wassermann reaction titre was was $1: 128$. Monthly tests for the next 4 months showed a Wassermann reaction titre ranging between $1: 64$ and $1: 128$; at no time was the Kahn or PPR positive. He was not seen again until 2 years after the original test when he was found to have a Wassermann reaction of $1: 64$. It is considered that this case is an example of the rare naturally occurring "biologic false positive". The case illustrates that not all biologic false positives will revert to negative in a short time (Paillard and Bolay, 1951). Since this paper was submitted for publication, this airman has been shown to have a negative treponemal immobilization test.

Case B86. - This case, of frank early primary syphilis, shows the characteristic pattern of tests in acute cases. At the first test the results were : Kahn + ; PPR, $1: 32$; Wassermann, 1:32; re-tested 10 days later to exclude clerical error, the results were Kahn + ; PPR, $1: 64$; Wassermann, $1: 128+; 6$ weeks after treatment was begun the PPR was negative and remained so. The Wassermann was $1: 16$ at 6 weeks, $1: 4$ at 10 and 14 weeks, and negative at 18 weeks. The Kahn was positive until the 18th week. All reactions were negative by the 24th week.

Case C19.-This patient was referred through the ophthalmic department as a case of iritis. The following results were found: Kahn + ; PPR, 1:2; Wassermann, $1: 64$. It was remarked that he had recently been vaccinated but infectious mononucleosis was not excluded. Ten days later the PPR was negative, Kahn +, Wassermann, 1:16. A fortnight later all tests were negative and remained so. No treatment which could have affected his serology was ever given. The low titre of the PPR was commented upon at the time as possibly indicating a false positive.

Case C525.-An airman had a typical history and signs of a non-specific urethritis appearing 10 days after exposure. He was treated with aureomycin while his serology was being investigated, but treatment was stopped when his results were found to be : Kahn + ; PPR - ; Wassermann, $1: 8$. On recall he stated that the day after examination he had developed a "lump in the pipe" which disappeared rapidly. His PPR was now positive at $1: 1$ and his Wassermann $1: 16 ; 14$ weeks after the original test all three reactions were again positive, and by 18 weeks the PPR titre was rising $(1: 4)$. He was then treated as a case of intraurethral chancre. The serology is interesting as it would seem that the course of aureomycin inhibited the emergence of a positive PPR.

Case G19.-This case was clinically diagnosed as late secondary syphilis. Pre-treatment tests showed Kahn + ; PPR, 1:8; Wassermann, 1:64. One month after treatment the PPR had fallen to $1: 2$ and the Wassermann to $1: 16$. At 2,3, and 4 months the PPR was negative, the Kahn positive, and the Wassermann ranged between $1: 4$ and $1: 8$. At 6 months all tests were negative, but at 10 months the Wassermann was positive alone at $1: 8$, and again at 12 months the Kahn and PPR were negative, the Wassermann being $1: 4$. All reactions were negative at 13 months and have remained so. This case illustrates the tendency for the Wassermann to remain positive the longest of the three reactions in the more chronic cases (see Case B86).

Case G231.-A recruit blood donor volunteer gave the following serological results : Kahn +, PPR - ; Wassermann, $1: 128+; 3$ weeks later the results were similar, save that the Wassermann titre was now $1: 32$. After a further month the Kahn was negative and the Wassermann $1: 4 ; 3$ months after the original test all reactions were negative and they have since remained so. No treatment was given. The interesting points are : first, the negative PPR firmly suggesting a false positive : secondly, the very high titre of the Wassermann associated with a negative PPR ; thirdly, the tendency for the Wassermann reaction to persist rather longer than the Kahn when both are biologically falsely positive. 